\title{
A CASE OF NEUROBLASTOMA
}

\author{
By W. Leach, M.A., M.B., B.Chir. \\ Formerly House Physician, The Connaught Hospital, Walthamstow
}

After Virchow first described adrenal tumours in children in 1864 , there were comparatively few cases reported until about 1938 . However, in the past 20 years cases of neuroblastoma have been reported with increasing frequency, and to some extent successful methods of treating them described in the literature. It is important that these rare tumours should be recognized as early as possible if treatment is to be at all effective. The following report describes the symptoms and progress of the disease from an early stage, and illustrates how this condition should be borne in mind when unexplained symptoms and signs persist in children, and when the disease originally diagnosed fails to respond to a prolonged course of standard therapy.

\section{Case Report}

The patient, a boy of 5 years 2 months, was admitted to the Connaught Hospital on November 9, 1955, complaining of a painful left hip for the previous four days.

In the past he had been a two weeks premature babe, weighing $5 \mathrm{lb} .8 \mathrm{oz}$. at birth. His mother claimed that he had always been a bad eater, but he had gained weight normally and was only a few pounds below average on admission. At the age of $2 \frac{1}{2}$ years he was thought to be walking abnormally and was given supports in his shoes for a year. Otherwise he seemed a fairly normal active child.

There was no family history of illness. He had healthy parents and a brother aged 4 .

In June 1955 , five months prior to admission, he began to suffer from transient pains in his calves and feet which were present for as short a time as a mere hour or so. He walked quite normally and his doctor treated these as growing pains. $\mathrm{He}$ went to school just after his fifth birthday and played with the other children. Four days prior to admission he was hit on the left buttock by another child; there had been pain around the left hip region since, and he had walked with a slight limp. Otherwise he was quite well in himself, eating as usual and had no other complaints.
On examination, he appeared to be a fit child. There was bilateral cervical lymphadenopathy and enlargement of the tonsils. The temperature was I00.4 rectally. He had tenderness along the left iliac crest, no sign of any trauma, and there was painful limitation of internal and external rotation of the left hip joint, but no muscle wasting.

The haemoglobin was found to be 70 per cent., the white cell count 10,000 with a normal differential, and the E.S.R. $45 \mathrm{~mm}$. $/ \mathrm{hr}$. X-ray of the hips, femora, left knee and lungs were normal and a Mantoux test was negative. He was put on skin traction for a fortnight, after which the pain, tenderness and limitation of movement disappeared from the hip, but he was found to be tender over the sternum. At that time, he was still running a low intermittent pyrexia and his E.S.R. was still raised, but there was no swelling of the joints, tenderness or rheumatic nodules.

A few days later he again complained of pain, this time in the left knee which he was unwilling to move. X-ray of the knee was normal. Towards the end of November he complained of pain and stiffness in his neck and was still running a temperature. At this point the case was referred to a Physician as being a probable case of rheumatic fever. This latter was agreed upon; treatment with salicylates was begun, and a throat infection was treated with the appropriate antibiotic. His condition whereupon appeared to improve and his pyrexia seemed to be settling, but a systolic murmur could now be heard over the apex of the heart.

However, at the end of December he again became pyrexial, his E.S.R. was raised to 66 $\mathrm{mm}$./hr., and his haemoglobin had fallen to 55 per cent. in spite of oral iron medicine.

At the end of January 1956, the patient once more complained of pain in the left knee and elsewhere in the neck. There was limitation of extension of the cervical spine and he had a temperature of 102 , but otherwise no abnormalities could be detected. An E.C.G. at this time was normal, and the blood investigations were unchanged. $\mathrm{He}$ was put on cortisone and in a few days the pains 


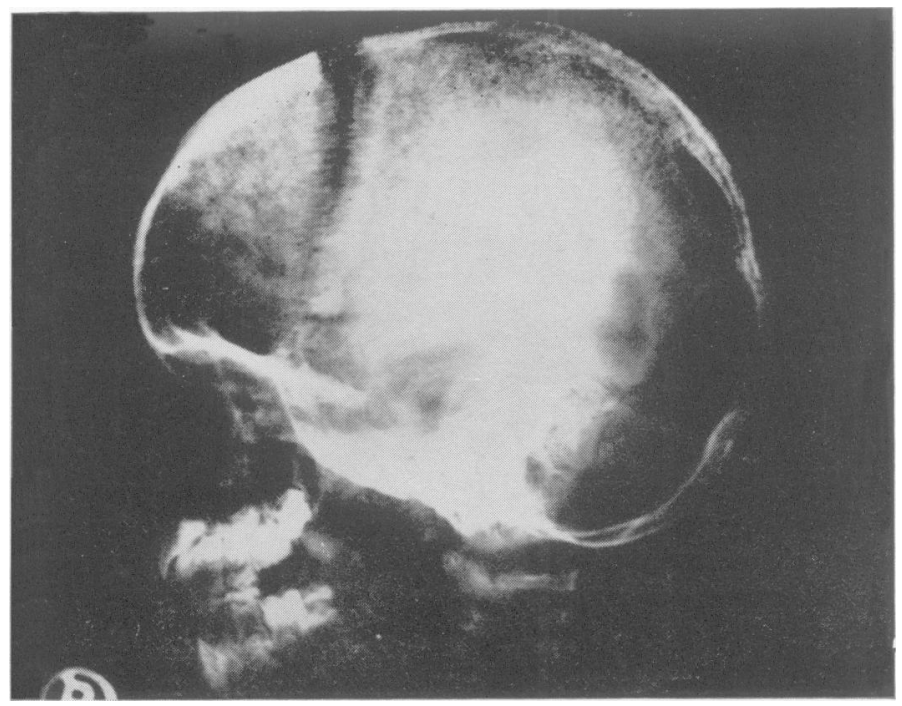

had gone, he was apyrexial and his E.S.R. was decreasing. The improvement continued; he was found to be gaining weight and the haemoglobin was rising.

On February 16, he developed pain and tenderness around the left orbit and was noticed to have proptosis on the left. An X-ray showed an opaque left antrum and ethmoid cells, and accordingly the cells and antrum were opened surgically and drained of much pus. After this the cortisone was stopped (after 26 days treatment) and he was put on an antibiotic again. His condition now seemed to improve once more.

On March 3, he complained of epigastric pain and vomited once. The abdomen was distended with gas, there was no guarding or rigidity and a straight X-ray of the abdomen was reported as normal. The faecal fat content was normal. The oral iron preparation was withdrawn and he was watched carefully. Next day the pain was worse and he had signs of meningeal irritation. Lumbar puncture revealed a normal C.S.F. The abdominal pain got better gradually over a few days to be succeeded by further pain, tenderness and swelling of the left knee joint. There was still no radiological evidence of any disease of the bones or joint.

He was now referred to an E.N.T. surgeon for an opinion as to whether tonsillectomy would benefit him and perhaps finally terminate the recurring pyrexia. A throat swab grew a normal selection of flora, but nevertheless tonsillectomy and adenoidectomy was thought advisable, and accordingly was carried out after he had been transfused with a pint of blood. After this he once more seemed to improve. The temperature settled for a week or so, and the E.S.R. came down.

On about April 7, the parents claimed that the child's eyesight was defective. He was seen by the consulting ophthalmologist, who thought the right disc was engorged but that there was no evidence of a visual field defect. It was about this time that he was first noticed to be developing one or two small lumps on the scalp. His E.S.R. and temperature were still raised and his haemoglobin had fallen again.

Towards the end of April, the original lumps on the scalp were noticed to be getting bigger and further small ones had appeared posteriorly. An $\mathrm{X}$-ray of the skull showed widening of the sagittal and coronal sutures and a worm-eaten rarefied appearance of the bones of the vault (Fig. I).

On May 2, the largest of the lumps on the left side in the temporo-frontal region had reached a diameter of about $4 \mathrm{~cm}$., and a second on the right side was about $3 \mathrm{~cm}$. across. There were three or four smaller ones towards the back of the scalp in the occipital region. The larger ones were smooth, cystic, non-tender lumps beneath the skin and not attached to it. Aspiration of each of the larger cystic lumps produced what appeared to be pure blood. Microscopically, this fluid was shown to consist of blood containing a high proportion of lymphocytes.

His E.S.R. at this time was $62 \mathrm{~mm}$./hr., his haemoglobin 54 per cent., and he was accordingly given a blood transfusion of two pints.

An intravenous pyelogram was performed on 


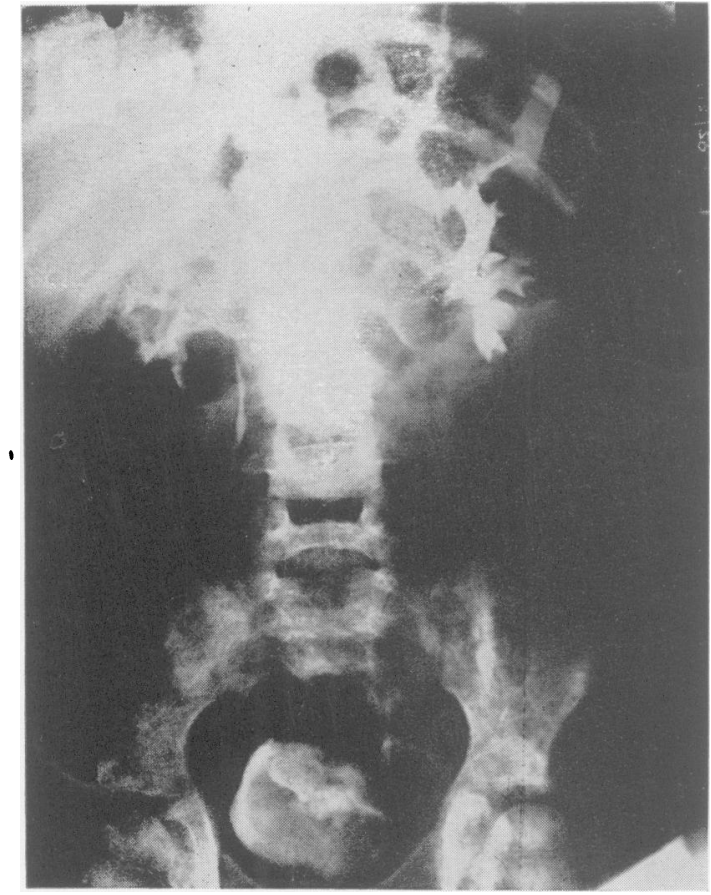

FIG. 2.-I.V.P. film showing displaced and more dilated calyces on the left side.

May 5, and showed a normal rate of excretion from both kidneys. The left kidney shadow was displaced laterally consistent with a space occupying peri-renal lesion. This, together with the relatively more dilated calyces of the left kidney, is well seen on the X-ray (Fig. 2), taken 20 minutes after injection of the dye. On the original X-ray film there was, in addition, evidence of erosion of the transverse process of the second lumbar vertebra, and numerous calcifications above the left suprarenal gland. Opacities in the I Ith intercostal space and overlying the I Ith rib, visible in a straight X-ray of the lumbar spine, represented the calcifications first seen in the I.V.P. film. The latter also showed extensive rarefaction of the pelvic bones shown more typically on the skull X-ray (Fig. I).

Biopsy of one of the lumps beneath the scalp was carried out next day. A deep brown, very vascular lesion was revealed, with the pericranium overlying it. It was subsequently shown microscopically to consist of highly vascular tissue, but showing mainly a deeply staining round cell arranged in groups, some showing delicate intercellular fibrils. Occasional groupings were suggestive of ' rosette' formation and the whole section was typical of a neuroblastoma.

A more careful examination of the patient now revealed enlarged, tender, deep inguinal glands in both groins, and enlarged superficial femoral glands in the left groin. There were a few smaller glands in each axilla. The eyes were prominent and there was definitely some degree of blindness. There was also increased vascularity evident in the skin of the left side of the forehead with dilatation of the superficial veins.

He was started on massive doses of vitamin $B_{12}$ (1,000 microgrammes alt. die) on May I I. A few days later he complained of pain and stiffness of the neck and was found to have further tender enlarged glands on both sides of the neck along the anterior and posterior borders of the sternomastoid. He was still running a temperature and the haemoglobin had fallen to 54 per cent.

At the beginning of June, he began to complain of pain in the left knee again, and also in the right forearm. His condition was obviously deteriorating, despite the massive vitamin $B_{12}$ therapy. He was very weak, thin and pale and had obvious bilateral proptosis, more so on the left. There were up to nine lumps palpable beneath the scalp varying in size from $1 \mathrm{~cm}$. in diameter upwards, the largest at the front on the left being about $6 \mathrm{~cm}$. across. None was tender, the smaller ones were solid, but the larger ones cystic. The anterior fontanelle and sutures were widely separated. There was more dilatation of the veins draining the scalp and more numerous glandular enlargements. The jugular venous pressure was raised $2 \mathrm{~cm}$. and there was a soft apical systolic murmur. There was increased basal resonance over the left lung posteriorly. In the abdomen, there was a tender, hard, irregular mass roughly $6 \mathrm{~cm}$. by 4 $\mathrm{cm}$. just below the left costal margin and well to the left of the mid line, felt on deep palpation. The liver was enlarged to one finger below the right costal margin in the nipple line.

The pupils were dilated and there was perception of light on the right side but none on the left. The optic disc on the right showed slight swelling and pallor, while the left disc was pale, but with no swelling.

There was localized bony tenderness on the right radius laterally near the elbow, and also on the lateral side of the left femur, just above the knee.

X-ray of the skeleton showed a patchy wormeaten appearance in the long bones, particularly the proximal portions of the femora and humeri, and similar appearances in the pelvis, clavicles, ribs and cranium. The coronal and sagittal sutures were widely separated. The bones of the hands and feet and the distal portions of the radius, ulna, tibia and fibula were unaffected. There was a localized area of periosteal elevation and underlying spicular formation on the lateral side of the 
left femur, just above the knee joint and a smaller similar area on the medial side of the left tibia, just below the knee joint. Calcification in the tumour was easily seen opposite DI I and I2, to the left of the mid line.

On June 4, a course of daily radiotherapy was begun, and the dose of vitamin $B_{12}$ was reduced to Ioo microgrammes twice weekly. It was proposed to irradiate the region of the tumour back and front with a small fractional dose of $\mathrm{X}$-rays and to irradiate the chief glandular enlargements in the lower half of the trunk later, but after the third treatment, when he had received a total of 15 or to the front and roor to the back, his condition was considered too poor and his haemoglobin too low ( 38 per cent.) for treatment to be continued. A few days later he was transfused with two pints of blood and his haemoglobin rose to 57 per cent., but his general condition was still very poor.

On June 16 , his condition was obviously deteriorating rapidly. He was incontinent, and had loss of sensation below the segmental level of Di2. Next day he became progressively weaker, very cyanosed and dyspnoeic, gradually sank into coma and died.

\section{Post Mortem}

External examination revealed a thin, pale, wasted boy of five. There was bilateral proptosis, with prominent subcutaneous vessels on the scalp, most marked in the frontal and temporal regions. The outline of the scalp was distorted by large hemispherical purple masses (up to $6 \mathrm{~cm}$. in diameter) situated on the vault and foreheadabout six in number. There were numerous enlarged glands in both posterior triangles of the neck extending from the angle of the jaw to the clavicle. There were enlarged glands in the left groin, the skin over them being purple in colour.

Reflection of the scalp revealed moderately well defined haemorrhagic tumour masses continuous with the underlying bone of the vault, and showing closely packed vertical striations on the cut surface. In places both the inner and outer tables were replaced by necrotic grumous tumour tissue, but the dura, though showing superficial infiltration on its outer aspect, was smooth and glistening, and free of invasion on its cerebral aspect. Both orbits appeared filled with tumour tissue invading adjacent bone structures. There was no microscopic evidence of secondary infiltration of cerebrum or cerebellum.

The heart was normal in size and the valves appeared normal. The myocardium showed signs of fatty degeneration.

The trachea and bronchi contained fluid mucus. Broncho-pneumonic areas were present at both lung bases.

In the abdomen, the liver was normal in size.

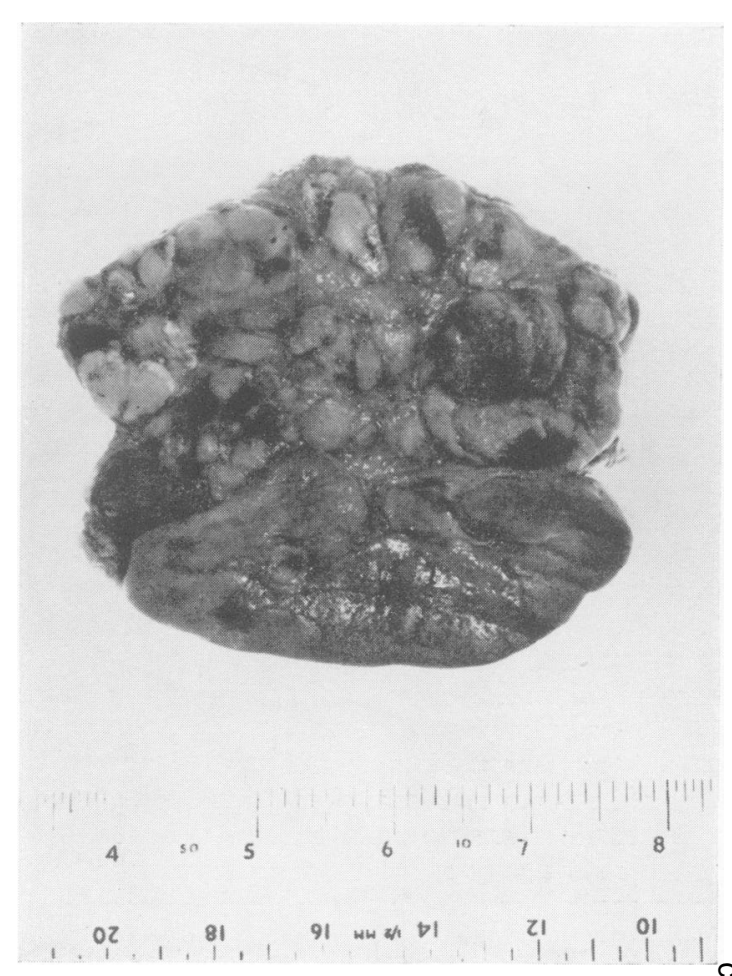

Fig. 3.-Tumour mass adjacent to left kidney.

There was a small pale nodule of secondary growth $1 \mathrm{~cm}$. in diameter in the left lobe. The spleen, stomach and intestines were normal. The left kidney was displaced laterally by massive growth of equivalent size, the cut surface of which was variegated, showing yellow necrotic areas, haemorrhage, greyish pink zones and flecks of calcification. Part of the left adrenal was involved in growth, as was also the tail of the pancreas (see Fig. 3). There were numerous infiltrated paraaortic glands on the left side extending down to the bifurcation, and a mass of glands extending above and below the left inguinal ligament. The right kidney and bladder appeared normal.

Growth was present also in several ribs and all the lumbar vertebrae showed extensive replacement by growth, causing partial collapse in the region of L.2.

The cause of death was disseminated neuroblastoma.

Histology revealed the typical deeply staining round cells, in some places being grouped into ' rosettes'. At least two ' rosettes ' are well shown in the photomicrograph (Fig. 4). Intercellular fibrils were also present. Sections from the main growth and from orbital, cranial and liver metastases showed a very similar pattern. 


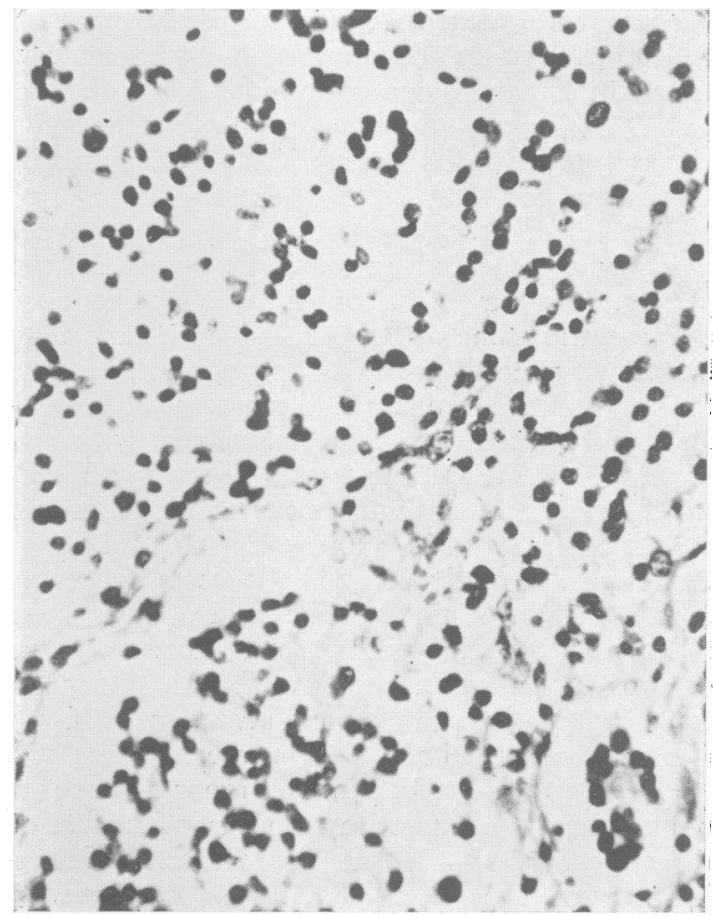

FIG. 4.-Photomicrograph of section from left perirenal tumours showing ' rosettes.' Enlarge $\times 450$ (microscope).

\section{Discussion}

One of the main points of interest in this case is the relatively late appearance of evidence leading to a conclusive diagnosis. Even though the patient had been under close clinical observation in hospital, with frequently repeated investigations, it was five months before the more characteristic signs of the ultimately diagnosed disease first made their appearance-namely defective vision and lumps in the scalp. It was then that the I.V.P. was carried out, pointing strongly to the presence of neuroblastoma and this was subsequently confirmed by biopsy. An earlier diagnosis in the absence of these more characteristic signs would have been most difficult to elucidate, in view of the rarity of the condition and the close similarity of the disease in its earlier stages to rheumatic fever with repeated relapses. However, on scrutinizing earlier X-rays, it was interesting that the areas of calcification first noticed in the I.V.P. films in association with other abnormalities, were present consistently, but to a less marked degree, in films taken three months or more previously.

Going back over the history of the case, it is significant that the site near the left knee, where pain was most often complained of, later became the site of a metastasis which was not shown on the earlier films. The occurrence of an acute ethmoiditis at one stage might have been a consequence of the early formation of orbital and paranasal metastases and their obstruction to the normal drainage of the sinuses. The effect of cortisone, prior to this episode, was interesting in that it caused a temporary amelioration in the patient's general condition, though whether it actually had any effect on the tumour cells is a matter for conjecture. The vitamin $B_{12}$ therapy was begun as soon as a definite diagnosis was established. This treatment has been tried only recently, and is said to encourage the necrosis of tumour cells and their transformation into the benign ganglioneuroma cells (The Lancet, Editorial, I954, ii, 585).

The post mortem findings fitted in well with what had been anticipated from clinical examination and X-ray. The loss of sensation and bladder control in the terminal stages are explained by the invasion of the lumbar vertebrae and pressure on the spinal cord by the growth. Separation of the sutures was due to the increased intracranial pressure caused by the tumour masses growing rapidly both internally and externally. It was impossible to define the exact site of origin of the primary tumour. It may have sprung from the left adrenal or from part of the left paravertebral sympathetic chain and both these were surrounded and infiltrated by the tumour cells. Unfortunately transformation into ganglioneuroma cells was not confirmed in the histology sections, in spite of the vitamin $B_{12}$ therapy.

\section{Earlier Reports}

Mention has already been made of Virchow, who is credited with the discovery of adrenal tumours, or 'gliomata' as he called them, in children. The clinical picture was first described in 1901 by Pepper, whose name became classically linked with right-sided tumours. He published six cases, all of which had died within a few weeks, showing the presence of a right-sided adrenal tumour associated with local extension to the liver and metastases in the liver, lungs and regional lymph glands. Pepper emphasized the rapid course and fatal termination in this disease. In I907, Robert Hutchinson quoted seven new cases and discussed three previously published ones in a paper on 'Suprarenal sarcoma in children with metastases in the skull.' He was the first to draw attention to this type of syndrome, adrenal tumours (mainly left-sided) associated with metastases in skull, ribs, long bones and orbits. None of his cases survived more than six months. The present case reported above showed very similar features to these early ones first published by Hutchinson 50 years ago. 
In 1908 , four more new cases were published by Tileston and Wolbach. J. H. Wright, in 1910, pointed out that the origins of this type of tumour were in the sympathetic nervous system. In I9I I, Frew published a collection of cases from the records of Great Ormond Street, 19 of which were left-sided tumours and 29 right-sided. Then two cases of cervical sympathetico-neuroblastoma were reported from Germany in I913, one by Martius and the other by Freund. Harvey Cushing and S. Burt Wolbach, in 1927 , described a remarkable case of a histologically confirmed transformation of a malignant paravertebral sympathetico-neuroblastoma into a benign ganglio-neuroma ten years later, after a course of bacterial toxins. A little later in 1932, Lehman published a case in which the patient survived I 5 years after neuroblastoma had been diagnosed; I I 4 cases were published by Redman et al. in 1938, in America, and in 1940, Wells reported 17 congenital cases.

In 1940 an important paper by Farber described 40 cases of neuroblastoma collected from the Boston Children's Hospital during the previous ten years. Ten of these 40 were still alive three to eight years after surgical removal of the tumour, with or without post-operative radiotherapy. Of other cases which survived, in some the tumour underwent spontaneous haemorrhage and necrosis and disappeared after only a biopsy, in others spontaneous maturation of the neuroblastoma cells to ganglioneuroma occurred, while in others treatment with radiotherapy was carried out successfully, even after metastasis had occurred.

Next year, Ladd and Gross reported seven cases surviving out of a series of 32 histologically verified neuroblastomata. Three of these seven had surgical excision only, a further three had excision followed by radiotherapy and one which was thought inoperable was still alive eight years later after no treatment at all.

In $195^{\circ}$, Brody reported neuroblastoma affecting one of twins, with a normal co-twin, and in the same year Harrison et al. reported a case which was still surviving three years after surgery with radiotherapy. Next there was a case published by Selby of neuroblastoma of extra-renal origin involving the ovaries, and then Silverstone et al. reported a three-year survival following radiotherapy only. Also in 1950, Wittenborg wrote an interesting paper on the treatment of these cases with radiotherapy and reviewed a series of 73 cases. He reported a 30 per cent. three-year survival rate in his series and concluded that early diagnosis followed by surgery and radiotherapy gave the best prognosis.

Next year, in $195 \mathrm{I}$, there was quite a number of reports, mainly of isolated cases, the authors of which are quoted in the bibliography. In addition,
Farber wrote describing marked regression of skeletal metastases after courses of such agents as $\frac{1}{2}$ aminoanfol, triethylene melamine and cortisone, $\stackrel{\propto}{\varrho}$ and Goldring reported regression of skeletal and $\complement$ visceral metastases following $\mathrm{X}$-ray therapy to the $\underset{\overrightarrow{9}}{\overrightarrow{7}}$ adrenal primary only.

A series of 31 cases were reported by Snyder et al., who remarked on persistent pyrexia in $60 \frac{\overline{0}}{\mathrm{~m}}$ per cent. of their cases. Since the early twentieth $\overparen{\Phi}$ century, the name of Pepper had been classically linked with the liver and lymph node metastases is from right-sided tumours, and the name of Hutch- $\overrightarrow{0}$ inson subsequently became associated with the syndrome of skeletal metastases indicating a left- $\vec{\omega}$ sided tumour, even though four of Hutchinson's cases had right-sided primary lesions. In $195 \mathrm{I}, 3$ Poore $e t$ al. carefully analysed 389 cases and came to the conclusion that the old classification was too rigid, and that in fact skeletal metastases are of common whichever adrenal is affected. In many or

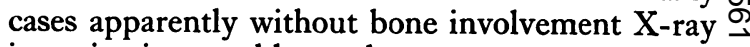
investigation would reveal metastases.

One or two isolated cases were reported in 1952, but the next and most important contribution of $z$ recent years was the Hunterian lecture on Neuroblastoma read to the Royal College of Surgeons in $\frac{\mathbb{}}{3}$ July 1952, by Ralph Phillips, assistant radiotherapeutist to the Memorial Center for Cancer and Allied Diseases, New York. A series of 623 col $\overrightarrow{0}$ lected cases were quoted from amongst his own. patients and those of others during the previous $2 \cdot 0$ years. From a smaller selected group of $1_{55}$, a three-year survival rate of 22.6 per cent. was given, and the various methods of treatment were quoted. It was mentioned that there seemed to be a natural $\stackrel{\odot}{\perp}$ tendency towards spontaneous remission by trans- $\overrightarrow{\vec{P}}$ formation of the acutely malignant tumour into the $\frac{9}{3}$ benign ganglioneuroma. Active treatment in the early stages might increase the chance of eventual survival by suppressing the initial malignant phase and encouraging maturation to the benign form. Therefore, a more hopeful attitude in treating these cases was advocated.

The most recent report is one by B. J. S. Grogono, in March I956, of a case at the Paddington General Hospital which presented with intra- 을 peritoneal haemorrhage. In spite of a combination of surgery, radiotherapy and massive vitamin $B_{12}$ 을 therapy, the patient died within four months.

\section{Summary}

A case of neuroblastoma occurring in a young child is presented and the progress and treatment is discussed. A brief history of earlier reports is 0 given and important previous work mentioned, including recent methods of treatment. The $\stackrel{\infty}{\rightarrow}$ importance of early recognition of these tumours is emphasized for treatment to be of benefit. 
I am grateful to Dr. A. A. G. Lewis, Physician to the Connaught Hospital, for his encouragement and for permission to publish this case. I also wish to thank Dr. H. Caplin for the post mortem and histology reports and his Laboratory Staff for preparing the photographs.

\section{BIBLIOGRAPHY}

ACKERMAN, L. V., and TAYLOR, F. H. (I95I), Cancer, 4, 609. ALEXANDER, R. C. (195I), Brit. F. Surg., 38, 5 r 7.

BARDEN, R. P., and LEWEY, F. H. (r 949), F. Neurosurg., 6, 439. BECK, S. M., and HOWARD, P. J. (1951), Amer. F. Dis. Child., 82,325 .

BENEVENTI, F. A., and TWINEM, F. P. (r948), f. Urol. (Baltimore), 60, 235 .

BLACKLOCK, J. W. S. (1934), f. Path. Bact., 39, 27.

BOYD, R. W. (1950), Canad. med. Ass. F., 63, 153.

BRODY, H. (1950), Amer. F. hum. Genet., 2, 37 r.

CHANDLER, F. A., and NORCROSS, J. R. (1940), 7. Amer. med. Ass., II4, I I 2.

Cline, P. A., et al. (1950), Amer. F. Roentgenol., 63, 246.

COLEY, B. L., HIGINBOTHAM, N. L., and BOWDEN, L. (1948), Ann. Surg., 128, 533.

COX, R. A. (1948), Arch. Ophthal. (Chicago), 39, 73I.

CUSHING, H., and WOLBACH, S. B. (1927), Amer. F. Path., 3, 203 .

DEDERICK, G. F., MILLS, S. D., and JUDD, E. S. (1950), Proc. Mayo Clin., 25, 618.

DUNN, J. S. (r915), f. Path. Bact., r9, 456.

FARBER, S. (1940), Amer. F. Dis. Child., 60, 749.

FARBER, S. (1951), ibid., 82, 239.

FREUND, P. (1913), Frankfurt Z. Path., 13, 266.

FREW, R. S. (r91 I), Quart. F. Med., 4, 123.

GOLDRING, D. (195I), 7. Pediat., 38, 23 I.

GROGONO, B. J. S. (1956), Brit. F. Surg., 43, 550.

HAMILTON, P. K. (195I), Amer. F. clin. Path., 21, 846.

HARRISON, F. G., WARRES, H. L., and FUST, J. A. (1950), f. Urol. (Baltimore), 63, 598.

HARVEY, R. M. (1950), Radiology, 54, 689.

HASSIN, G. B., and MUNCH-PETERSEN, C. J. (1950), Trans. Amer. neurol. Ass., p. 108.

HACSER, H. (1934), Amer. F. Roentgenol., 31, 234.
HLDSON, H. W. CHAMBERLAIN, J. W, and BECKER, F. B. (1952), New Engl. 7. Med., 246, 536.

HUTCHINSON, R. (1907), Quart. F. Med., I, 33.

JUDGE, D. J., et al. (1949), Clin. Proc. Child. Hosp. (Wash.), 5 , 115 .

KATO, K., and WACHTER, H. E. (1938), F. Pediat., 12, 449.

KERLEY, C. G. (1940), Amer. F. Dis. Child., 60, 750.

LADD, W. E., and GROSS, R. E. (1953), 'Abdominal Surgery of 'Infancy and Childhood', p. 606. W. B. Saunders, Philadelphia.

LEHMAN, E. P. (1917), F. med. Res., 36, 309.

LEHMAN, E. P. (1932), Ann. Surg., 95, 473.

LOOMIS, E. A., and LOOMIS, G. L. (1949), Minn. Med., 32, 605

LOLRIA, M. R. (1949), Dis. Chest, 16, 75.

MANDEVILLE, F. B. (1949), Radiology, 53, 403.

MANDEVILLE, F. B. (1947), Crol. cutan. Rer., 5, 448.

MARTILS, K. (I913), Frankfurt $Z$. Path., 12, 442.

MLRRAY, M. R., and STOLT, A. P. (1947), Amer. F. Path. 23, 429 .

PEPPER, W. (1901), Amer. F. med. Sci., 121, 287.

PHILlIPS, R. (1953), Ann. roy. Coll. Surg. Engl., 12, 29.

PINEY, A., MALLARME, J., and ROSS, M. S. (1950), f. clin. Path., 3, 230.

POORE, T. N., DOCKERTY II B KENNEDY, R. L. J, and

WALTERS, W. (195I), Surg. Clin. N. Amer., 31, I I 2 I.

REDMAN, J. L., et al. (1938), Amer. F. Dis. Child., 56, ro97.

REED, N. W. (1950), Arch. Pediat., 67, 447.

SCHRODER, J. R. (1949), Wis. med. F., 48, rooo.

SCOTT, E., OLIVER, M. G., and OLIVER, M. H. (r933), Amer. 7. Cancer, 17, 396.

SELBY, S. (1950), Arch. Dis. Child., 25, 4 r r.

SILVERSTONE, S. M., and HARRIS, W. (1950), f. Mt Sinai Hosp., 17, 1083 .

SMITH, B. H., and HALL, W. H. (1949), Nar. med. Bull., 49, 326. SMITH, C. A. (1948), F. Crol. (Baltimore), 60, 697.

SNYDER, W. H., et al. (1951), Arch. Surg., 63, 26.

STEWART, F. W. (1952), Tex. Rep. Biol. Med., ro, 239.

THO, A. (1948), Nord. Med., 40, 221 I.

VAN CREVELD, S., and VAN DAM, R. (1948), Qilart. Rei. Pediat., 3, 313 .

WEICKER, H. (1950), Ibid., 5, 266.

WELLS, H. G. (1940), Arch. Path., 30, 535.

WITTENBORG, M. H. (1950), Radiology', 54, 679.

WRIGHT, J. H. (1910), ₹. exp. Med., 12, 556.

WYATT, G. M., and FARBER, S. (194I), Amer. F. Roentgenol., 46,485 .

An Address Book for the Medical profession, showing how to reach the various Colleges, Societies, Institutes and Hospitals in or near London Now (Fourth) Edition: 1954

Price 2s. 6d. (2s. 10d., post free) 